\title{
Article
}

\section{Crypto Asset Portfolio Selection}

\author{
Daniel Felix Ahelegbey ${ }^{1, *}\left(\mathbb{D}\right.$, Paolo Giudici $^{1}(\mathbb{D})$ and Fatemeh Mojtahedi ${ }^{2} \mathbb{C}$ \\ 1 Department of Economics and Management, University of Pavia, 27100 Pavia, Italy; paolo.giudici@unipv.it \\ 2 Department of Agricultural Economics, Sari Agricultural Sciences and Natural Resources University, \\ Sari 48181-6898, Iran; fateme.mojtahedi87@yahoo.com \\ * Correspondence: danielfelix.ahelegbey@unipv.it
}

Citation: Ahelegbey, D.F.; Giudici, P.; Mojtahedi, F. Crypto Asset Portfolio Selection. FinTech 2022, 1, 63-71. https://doi.org/10.3390/ fintech1010005

Academic Editor: David Roubaud

Received: 14 December 2021 Accepted: 16 February 2022 Published: 21 February 2022

Publisher's Note: MDPI stays neutral with regard to jurisdictional claims in published maps and institutional affiliations.

Copyright: (C) 2022 by the authors. Licensee MDPI, Basel, Switzerland. This article is an open access article distributed under the terms and conditions of the Creative Commons Attribution (CC BY) license (https:// creativecommons.org/licenses/by/ $4.0 /)$.

\begin{abstract}
The aim of this paper is to propose a portfolio selection methodology capable to take into account asset tail co-movements as additional constraints in Markowitz model. We apply the methodology to the observed time series of the 10 largest crypto assets, in terms of market capitalization, over the period 20 September 2017-31 December 2020 (1200 daily observations). The results indicate that the portfolios selected considering tail risk are more diversified and, therefore, more resilient to financial shocks.
\end{abstract}

Keywords: portfolio selection; tail risk; extreme downside; systemic risk; systematic risk

\section{Introduction}

Portfolio optimization is one of the most widely studied problems in finance. A special case is to find portfolio weights that minimize the risk for a given desired return. This is achieved by selecting assets and deciding how many shares of capital to invest in each of them. In [1], the concept of mean-variance (MV) portfolio selection was formalized by using the variance of returns on investment as a measure of risk. This implicitly assumes that all risks in a portfolio can be represented by the variance of returns.

The extension of the MV assumptions has led to several studies of the portfolio optimization problem. While some have improved the return-risk approach modifying the reference theoretical background, under expected utility and stochastic dominance approaches, see [2-7], others remained within the MV paradigm with the inclusion of additional constraints, see [8-12]. We follow the latter stream of research and focus on the inclusion of systematic risk in risk-return portfolio selection. Our model is based on the work of [13] who generalized the concept of systematic risk to a broad class of risk measures. They proposed an equilibrium framework that generalizes the Capital Asset Pricing Model and an axiomatic approach which leads to a systematic risk measure as the unique solution to a risk allocation problem.

However, systematic risk is not the only cause of return volatilities. Especially after the Great Financial Crisis, researchers have understood the importance of systemic risk, i.e., the inherent vulnerability of the financial system that propagates initial shocks leading to the failure of many institutions, whose cascading effects may endanger the whole system [14-22]. The recent financial crisis provides ample evidence of the importance of containing systemic risks. A further cause of return volatilities, frequent among crypto assets, is tail risk [23-27]. The importance of tail risk is well known in crypto asset markets, which often exhibit very high volatility.

Recently, a number of papers underlined the importance of including either systemic or tail risk in portfolio optimization, see [28-30]. In [30], a Bayesian decision theoretical framework was introduced; ref. [28] presented an approach for dynamic portfolio selection; ref. [31] applied a differential evolution algorithm; ref. [32] considered a nonlinear multiobjective mathematical model; ref. [33] proposed a multiperiod robust selection with an asymmetric uncertainty distribution, using lower partial moments to control the downside losses of the portfolio; ref. [34] investigated how the presence of systematic skewness 
constraints can influence portfolio selection; and [35] focused on downside risk based on the Value-at-Risk.

To date, there are no papers that consider tail risk as a constraint in portfolio selection. We propose to fill this gap by embedding tail risk measures within the portfolio framework proposed by [36]. Doing so, we provide a methodology to select portfolios that take into account tail risk and is, therefore, particularly suited to build crypto asset portfolios.

\section{Methodology}

Suppose that there are $n$ risky assets in the financial market, and let $R=\left(R_{1}, \ldots, R_{n}\right)$ denote the vector of random returns of these assets. Assume that the mean vector and the covariance matrix of $R$ are denoted by $\mu=\left(\mu_{1}, \ldots, \mu_{n}\right)$ and $\Sigma=\left\{\sigma_{i j}\right\}$, respectively. Furthermore, let $x=\left(x_{1}, \ldots, x_{n}\right)$ denote a portfolio-a vector of asset weights-and $P(x)=R^{\prime} x$ its return. The expected return and variance of the portfolio are $\mu^{\prime} x$ and $x^{\prime} \Sigma x$, respectively. The Markowitz Mean Variance portfolio selection model can be formulated as:

$$
\begin{array}{cl}
\min & \tau x^{\prime} \Sigma x-\mu^{\prime} x \\
\text { s.t. } & \mathfrak{e}^{\prime} x=1, \quad x \geq 0
\end{array}
$$

where $\mathfrak{e}$ is an $n \times 1$ vector of ones and $\tau \geq 0$ is a risk aversion parameter. The expected variance of the portfolio, $V(x)$, can be expressed as

$$
V(x)=x^{\prime} \Sigma x=\operatorname{tr}\left(\Sigma x x^{\prime}\right)=\sum_{i=1}^{n} \Psi_{i i}(x)=\sum_{i=1}^{n} \sum_{j=1}^{n} \sigma_{i j} x_{i} x_{j}
$$

where $\Psi(x)=\Sigma x x^{\prime}$ and $\operatorname{tr}()$ is the trace operator (the sum of the diagonal elements).

The Markowitz model has been extended by [37] in a formulation that makes explicit the dependence of the portfolio risk on a systematic factor, measured by the market index returns. The authors proposed the portfolio selection with constraints on allocation of systematic risk. Here, we extend the approach to consider tail risk, with the following definition.

Definition 1. Let $\Sigma=\left\{\sigma_{i j}\right\}$ be the covariance matrix $n$-assets and $x=\left(x_{1}, \ldots, x_{n}\right)$ denote a vector of asset weights. The risk contribution of asset-i is measured by the difference between total variance, $V(x)$ and the variance calculated without asset- $i, V\left(x_{-i}\right)$ :

$$
V(x)-V\left(x_{-i}\right)=\sigma_{i i} x_{i}^{2}+2 \sum_{i=1, i \neq j}^{n} \sigma_{i j} x_{j} x_{i}
$$

To establish the above relationship, we begin by considering an $n=3$-assets portfolio whose covariance matrix is $\Sigma=\left\{\sigma_{i j}\right\}$ and weights $\left(x_{i}, x_{j}, x_{k}\right)$. The expected variance of the portfolio, $V(x)$, from (2) is

$$
\begin{aligned}
V(x) & =\operatorname{tr}\left(\Sigma x x^{\prime}\right)=\operatorname{tr}\left[\left(\begin{array}{ccc}
\sigma_{i i} & \sigma_{i j} & \sigma_{i k} \\
\sigma_{j i} & \sigma_{j j} & \sigma_{j k} \\
\sigma_{k i} & \sigma_{k j} & \sigma_{k k}
\end{array}\right)\left(\begin{array}{ccc}
x_{i}^{2} & x_{i} x_{j} & x_{i} x_{k} \\
x_{j} x_{i} & x_{j}^{2} & x_{j} x_{k} \\
x_{k} x_{i} & x_{k} x_{j} & x_{k}^{2}
\end{array}\right)\right] \\
& =\sigma_{i i} x_{i}^{2}+\sigma_{j j} x_{j}^{2}+\sigma_{k k} x_{k}^{2}+2 \sigma_{i j} x_{i} x_{j}+2 \sigma_{i k} x_{i} x_{k}+2 \sigma_{j k} x_{j} x_{k}
\end{aligned}
$$

The expected variance of the portfolio without asset- $i, V\left(x_{-i}\right)$, is

$$
\begin{aligned}
V\left(x_{-i}\right) & =\operatorname{tr}\left(\sum x_{-i} x_{-i}^{\prime}\right)=\operatorname{tr}\left[\left(\begin{array}{ccc}
\sigma_{i i} & \sigma_{i j} & \sigma_{i k} \\
\sigma_{j i} & \sigma_{j j} & \sigma_{j k} \\
\sigma_{k i} & \sigma_{k j} & \sigma_{k k}
\end{array}\right)\left(\begin{array}{ccc}
0 & 0 & 0 \\
0 & x_{j}^{2} & x_{j} x_{k} \\
0 & x_{k} x_{j} & x_{k}^{2}
\end{array}\right)\right] \\
& =\sigma_{j j} x_{j}^{2}+\sigma_{k k} x_{k}^{2}+2 \sigma_{j k} x_{j} x_{k}
\end{aligned}
$$


The risk contribution of asset- $i$ is measured by

$$
V_{i}(x)=V(x)-V\left(x_{-i}\right)=\sigma_{i i} x_{i}^{2}+2 \sigma_{i j} x_{i} x_{j}+2 \sigma_{i k} x_{i} x_{k}
$$

It is expected that the portfolio variance must equal the sum of all assets' risk contributions to the overall index. However, in general and according to the expression in (3), $V(x) \neq \sum_{i} V_{i}(x)$, this is due to the fact that the terms $\sigma_{i j} x_{i} x_{j}$ and $\sigma_{i k} x_{i} x_{k}$ are doubly counted in the risk contributions of both assets $i$ and $j$, and $i$ and $k$, respectively. As discussed in $[16,38]$, a common approach to overcome this drawback is to decompose the common term $2 \sigma_{i j} x_{i} x_{j}$ in $V_{i}(x)$ and $V_{k}(x)$ into two terms as follows:

$$
2 \sigma_{i j} x_{i} x_{j}=\eta_{i j} 2 \sigma_{i j} x_{i} x_{j}+\left(1-\eta_{i j}\right) 2 \sigma_{i j} x_{i} x_{j}, \quad 0<\eta_{i j}<1
$$

where $\eta_{i j}$ distributes the common term $2 \sigma_{i j} x_{i} x_{j}$ into $V_{i}(x)$ and $V_{k}(x)$ in proportion to the volatilities of the assets $i$ and $k$, respectively.

Following the decomposition above, the risk contribution of asset- $i$ in a portfolio $x=\left(x_{1}, \ldots, x_{n}\right)$ is then defined as $[16,38]$

$$
V_{i}(x)=\sigma_{i i} x_{i}^{2}+2 \sum_{j=1, i \neq j}^{n} \eta_{i j} \sigma_{i j} x_{j} x_{i}
$$

Definition 2. Let $\Sigma=\left\{\sigma_{i j}\right\}$ be the covariance matrix $n$-assets and $x=\left(x_{1}, \ldots, x_{n}\right)$ denote a vector of asset weights. Let $\eta_{i j}=1 / 2$ for all $i$ and $j$. We measure the marginal risk contribution of asset-i, $\operatorname{MRC}_{i}(x)$, by

$$
\operatorname{MRC}_{i}(x)=\sum_{j=1}^{n} \sigma_{i j} x_{i} x_{j}=\Psi_{i i}(x)
$$

From the above definition, $V(x)=\sum_{i} M R C_{i}(x)$ is now achieved by the modified definition of marginal risk contribution in (9). We remark that the $M R C_{i}(x)$ measure adapts the marginal risk measure of [37], introduced to measure systematic risk, to the systemic risk framework. In their work, the authors assumed the marginal systematic risk of an asset is controlled by a systematic risk regulation parameter. In [39], each asset's marginal contribution to portfolio risk is proportional to its beta with respect to the portfolio. Following this line of reasoning, we assume the marginal risk contribution of each asset is controlled by a regulation parameter $\lambda$, which is related to the tail betas with respect to the portfolio, such that, $M R C_{i}(x) \leq \lambda_{i}, i \in \mathcal{C} \subseteq\{1,2, \ldots, n\}$, where $\mathcal{C}$ is the collection of assets whose risk contribution should be restricted. We consider $\lambda_{i}$ as a tail risk tolerance measure that expresses an asset's volatility in relation to other assets and the overall market in turbulent or crisis times.

Let $Y_{i, t}=E S_{\alpha}\left(R_{i, t}\right)$ denote the expected shortfall (the average value-at-risk) at tail probability $\alpha$ of asset- $i$ at time $t$. The EDH model of [40] expresses the returns at time $t$ of asset- $i$, for $i=1, \ldots, n$, as a function of the variation of the expected shortfall of the other assets and of the market, as follows:

$$
R_{i, t}=\sum_{j=1, i>j}^{n} B_{i j} \Delta Y_{j, t}+\beta_{i m} \Delta Y_{m, t}+\epsilon_{i, t}, \quad \epsilon_{t} \sim \mathcal{N}\left(0, \Sigma_{\epsilon}\right)
$$

where $\Delta Y_{j, t}=Y_{j, t}-Y_{j, t-1}$ and $\Delta Y_{m, t}=Y_{m, t}-Y_{m, t-1}$, whereas $B_{i j}$ and $\beta_{i m}$ are the sensitivity of the returns of asset- $i$ to the tail risk of asset- $j$ and to the tail risk of the market index, respectively, and $\epsilon_{i, t}$ is a residual term, that is, the part of the returns of asset- $i$ which cannot be explained by the returns of other assets, or by those of the market.

We extend the additional tail risk constraint of our portfolio selection with the following definition. 
Definition 3. Let $\left(Y_{1}, \ldots, Y_{n}\right)$ be expected shortfalls of n-assets and $Y_{m}$ denote the expected shortfall of the market index. Let $B$ denote the $n \times n$ full (non-symmetric) matrix and $\beta_{m}$ an $n \times 1$ vector of tail beta's with respect to the portfolio. Let $W=\left(B, \beta_{m}\right)$ and $\Omega=W W^{\prime}$. We measure the tail risk tolerance by

$$
\Lambda=\frac{1}{n} \operatorname{diag}(\Omega)
$$

We illustrate the $\Lambda$ computation by considering $n=3$ assets with expected shortfall series $\left(Y_{i}, Y_{j}, Y_{k}\right)$ and $Y_{m}$ as the expected shortfall of the market index. Let $W=\left(B, \beta_{m}\right)$ the matrix of EDH coefficients, thus:

$$
W=\left(B, \beta_{m}\right)=\left(\begin{array}{cccc}
0 & b_{i j} & b_{i k} & \beta_{i m} \\
b_{j i} & 0 & b_{j k} & \beta_{j m} \\
b_{k i} & b_{k j} & 0 & \beta_{k m}
\end{array}\right)
$$

Then

$$
\begin{aligned}
& \Omega=W W^{\prime}=\left(\begin{array}{ccc}
b_{i j}^{2}+b_{i k}^{2}+\beta_{i m}^{2} & b_{i k} b_{j k}+\beta_{i m} \beta_{j m} & b_{i j} b_{k j}+\beta_{i m} \beta_{k m} \\
b_{j k} b_{i k}+\beta_{j m} \beta_{i m} & b_{j i}^{2}+b_{j k}^{2}+\beta_{j m}^{2} & b_{j i} b_{k i}+\beta_{j m} \beta_{k m} \\
b_{k j} b_{i j}+\beta_{k m} \beta_{i m} & b_{k i} b_{j i}+\beta_{k m} \beta_{j m} & b_{k i}^{2}+b_{k j}^{2}+\beta_{k m}^{2}
\end{array}\right) \\
& \Lambda=\frac{1}{n} \operatorname{diag}(\Omega)=\frac{1}{n}\left(\begin{array}{c}
b_{i j}^{2}+b_{i k}^{2}+\beta_{i m}^{2} \\
b_{j i}^{2}+b_{j k}^{2}+\beta_{j m}^{2} \\
b_{k i}^{2}+b_{k j}^{2}+\beta_{k m}^{2}
\end{array}\right)
\end{aligned}
$$

Thus, $\Lambda$ measures the average tail exposure among assets and with the market index.

The intuition behind our $\Lambda$ measure is based on the fact that if there are no interactions, in which case $B=0$, then each asset's marginal contribution to portfolio variance is constrained by its squared beta measure with respect to the market index. However, if there are systemic interactions, in which case $B \neq 0$, then each asset's marginal contribution to portfolio variance is constrained to the average of the squared betas with respect to the market index and other assets.

The optimal portfolio will then be obtained as follows:

$$
\begin{array}{cl}
\min & \tau x^{\prime} \Sigma x-\mu^{\prime} x \\
\text { s.t. } & \operatorname{MRC}_{i}(x) \leq \lambda_{i}, \quad i \in \mathcal{C} \subseteq\{1,2, \ldots, n\} \\
& \mathfrak{e}^{\prime} x=1, \quad x \geq 0
\end{array}
$$

where $x$ is a vector of portfolio weights, $\Sigma$ the variance-covariance matrix of the returns, $\mu$ is the vector of average return, $M R C_{i}(x)$ is the marginal risk contribution of asset- $i, \tau$ is a parameter representing the risk aversion of investors, $\lambda_{i}$ is a tail risk tolerance parameter for asset- $i, \mathfrak{e}$ is an $n \times 1$ vector of ones, and $\mathcal{C}$ is the collection of assets whose risk contribution should be restricted. The comparison of Equation (12) with Equation (1) underlines our contribution to Markowitz' portfolio selection: the inclusion of a risk constraint which depends on two components: a systematic tail sensitivity component, expressed by $\beta_{m}$, and a pairwise tail sensitivity component, expressed by $B$.

\section{Empirical Findings}

We apply the proposed methodology to the 10 most capitalized crypto assets from the CoinMarketCap database (accessed on 21 January 2021) (https:/ / coinmarketcap.com/), using return time series from 20 September 2017-31 December 2020. More precisely, we analyze the return series of Bitcoin (BTC), Ethereum (ETH), Ripple (XRP), Bitcoin Cash (BCH), Litecoin (LTC), Binance Coin (BNB), Eos (EOS), Stellar (XLM), Chain-Link (LNK), Tron (TRX). As a market index, we consider the CRIX Crypto Index (CRX) see [41]. 
We assume that short selling is not allowed. To understand the time dynamics of the returns, we plot the crypto-asset log price series in Figure 1. Due to differences in the values, plotting the original log prices would make it difficult to visualize some of them. To overcome this limitation, we standardize each series to a zero mean and unit variance and add the absolute minimum value of each series. This keeps the values positive and standardizes the scale of measurement for the different series.

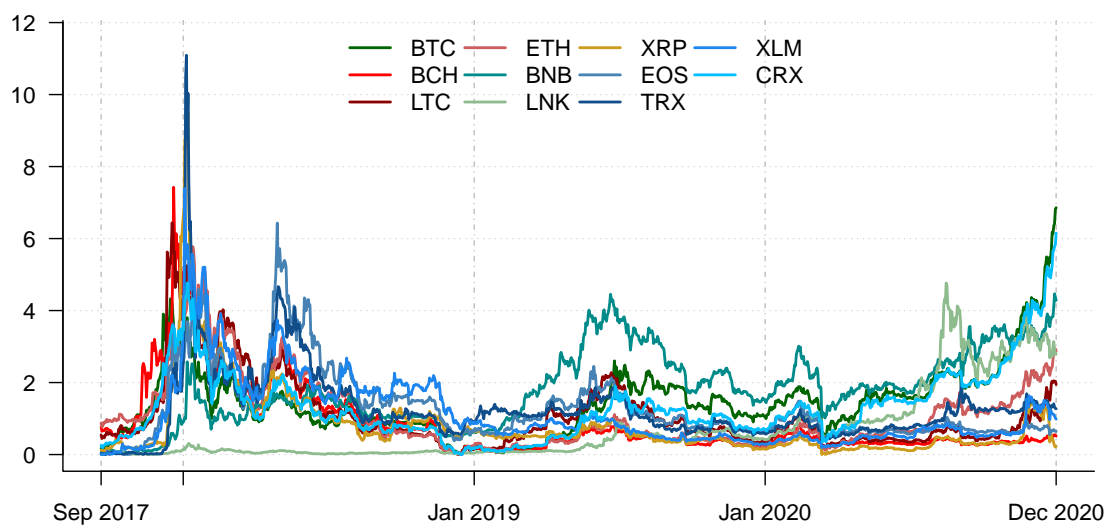

Figure 1. Normalized crypto-asset price series.

Figure 1 shows that the price of the cryptocurrencies had several fluctuations over time, but from the first months of 2020 we see an increasing trend, which remained until the end of the year. We report in Table 1 the summary statistics of the log-return series and first-difference of conditional value at risk (CVaR, or Expected Shortfall).

Table 1. Statistics for crypto-assets returns and first-difference of conditional value at risk (CVaR).

\begin{tabular}{llcccccccc}
\hline & \multicolumn{9}{c}{ Returns } \\
\hline Code & Name & Mean & Sd & Skew & Ex.Kurt & Mean & Sd & Skew & Ex.Kurt \\
\hline BTC & Bitcoin & 0.17 & 4.15 & -1.08 & 15.61 & -0.00 & 1.63 & -3.56 & 213.77 \\
BCH & Bitcoin-Cash & -0.03 & 6.78 & 0.07 & 10.40 & 0.00 & 2.98 & 2.15 & 104.04 \\
LTC & Litecoin & 0.07 & 5.54 & 0.37 & 9.02 & 0.00 & 1.91 & -1.80 & 117.23 \\
ETH & Ethereum & 0.08 & 5.09 & -1.22 & 13.19 & 0.00 & 1.88 & -4.94 & 240.10 \\
BNB & Binance-Coin & 0.33 & 6.09 & 0.23 & 12.99 & -0.01 & 1.72 & -5.59 & 265.12 \\
LNK & Chain-Link & 0.34 & 7.76 & 0.18 & 6.93 & -0.01 & 2.06 & -0.13 & 224.65 \\
XRP & Ripple & 0.02 & 6.34 & 0.98 & 20.64 & 0.04 & 2.91 & 6.97 & 118.03 \\
EOS & EOS & 0.12 & 6.70 & 0.20 & 7.10 & 0.01 & 2.27 & -0.66 & 96.15 \\
TRX & Tron & 0.19 & 8.27 & 1.94 & 20.58 & -0.02 & 2.79 & 0.87 & 178.97 \\
XLM & Stellar & 0.20 & 6.89 & 1.41 & 13.12 & -0.02 & 2.21 & 3.75 & 117.72 \\
CRX & CRIX & 0.17 & 4.19 & -1.37 & 13.94 & 0.00 & 1.61 & -2.02 & 181.68 \\
\hline
\end{tabular}

The table shows that the average of the daily return series are all close to zero, which is in line with the economic theory regarding asset returns. However, the 10 crypto assets exhibit different variability in returns. In particular, BTC shows the lowest variability, and TRX the highest. The skewness of the returns varies between -1.37 for CRIX and 1.94 for TRX, with BTC, ETH and CRX exhibiting negative skewness, while the rest display positive skewness. The excess kurtosis varies between 6.93 to 20.64, indicating, for all series, a leptokurtic behavior which reflects the non-Gaussian and heavy tailed behaviour of their associated distribution.

Since the returns are non-Gaussian with heavy tailed behaviours, we applied the Cornish-Fisher approximation to estimate the conditional value at risk (CVaR, or Expected Shortfall) for each asset via a 30-day period rolling estimation of daily returns. The summary statistics of the $\triangle \mathrm{CVaR}$, calculated averaging the values from each rolling window, are also reported in Table 1 . 
Table 2 shows the correlation matrix of asset returns, based on data from 20 September 2017-31 December 2020. The largest correlation is between ETH and LTC with a degree of association equal to 0.82 . The next largest correlation is between ETH and BTC, with a correlation coefficient of 0.76 , while that of BTC and LTC is 0.74 . From the results of the correlation matrix, we will expect our portfolio not to include at least two of these three crypto assets, i.e., ETH, LTC, and BTC.

Table 2. The correlation matrix of asset returns, based on data from 20 September 2017-31 December 2020.

\begin{tabular}{cccccccccccc}
\hline & BTC & BCH & LTC & ETH & BNB & LNK & XRP & EOS & TRX & XLM & CRX \\
\hline BTC & 1 & 0.63 & 0.74 & 0.76 & 0.63 & 0.46 & 0.51 & 0.64 & 0.54 & 0.53 & 0.11 \\
BCH & 0.63 & 1 & 0.66 & 0.72 & 0.49 & 0.41 & 0.54 & 0.67 & 0.44 & 0.49 & 0.05 \\
LTC & 0.74 & 0.66 & 1 & 0.82 & 0.59 & 0.45 & 0.60 & 0.69 & 0.51 & 0.55 & 0.03 \\
ETH & 0.76 & 0.72 & 0.82 & 1 & 0.62 & 0.56 & 0.66 & 0.73 & 0.58 & 0.61 & 0.03 \\
BNB & 0.63 & 0.49 & 0.59 & 0.62 & 1 & 0.44 & 0.44 & 0.55 & 0.44 & 0.47 & 0.04 \\
LNK & 0.46 & 0.41 & 0.45 & 0.56 & 0.44 & 1 & 0.43 & 0.46 & 0.40 & 0.46 & -0.01 \\
XRP & 0.51 & 0.54 & 0.60 & 0.66 & 0.44 & 0.43 & 1 & 0.61 & 0.52 & 0.64 & 0.04 \\
EOS & 0.64 & 0.67 & 0.69 & 0.73 & 0.55 & 0.46 & 0.61 & 1 & 0.56 & 0.56 & 0.04 \\
TRX & 0.54 & 0.44 & 0.51 & 0.58 & 0.44 & 0.40 & 0.52 & 0.56 & 1 & 0.44 & 0.08 \\
XLM & 0.53 & 0.49 & 0.55 & 0.61 & 0.47 & 0.46 & 0.64 & 0.56 & 0.44 & 1 & 0.06 \\
CRX & 0.11 & 0.05 & 0.03 & 0.03 & 0.04 & -0.01 & 0.04 & 0.04 & 0.08 & 0.06 & 1 \\
\hline
\end{tabular}

Although this is not the focus of the paper, we remark that the correlation among crypto returns may have changed over the years, particularly due to the impact of COVID19 (see e.g., [42]).

We now apply our portfolio selection model based on the crypto asset returns of the years 2018, 2019 and 2020. Before doing so, we present in Figure 2a graphical representation of the tail dependence among the different crypto currencies, following the model in (10). This can help in understanding the impact of both the tail and the systemic risk component on the chosen portfolio weights. Once the Extreme Downside Hedge $(\mathrm{EDH})$ value are calculated, we can determine the optimal portfolio according to our proposed model in (12).

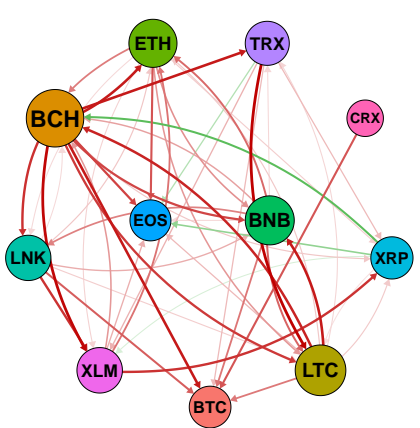

(a)

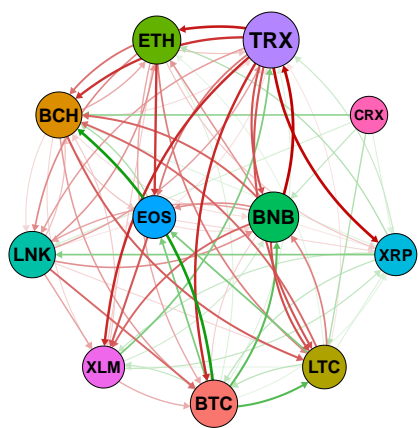

(b)

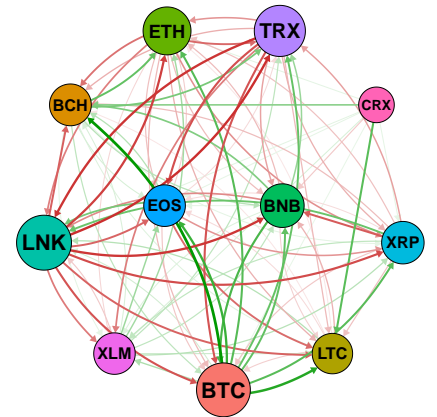

(c)

Figure 2. Tail dependence networks among crypto assets. A red link indicates a negative dependence; a green link a positive effect, and the bolder the link the higher the magnitude of the correlation. (a) 2018, (b) 2019, (c) 2020 .

Figure 2 shows that the strongest tail dependencies are connected with Bitcoin and Bitcoin Cash; they are mostly negative in 2018 and 2019, and mostly positive in 2020.

For comparison purposes, we present in Tables 3 and 4 the optimal portfolio selection via the EDH and Markowitz method, respectively. We do so by reporting the optimal portfolio weights for the years 2018, 2019 and 2020, under two values of the risk aversion parameter: $\tau=0.5$ and $\tau=5$. The choice of the different risk aversion parameter is to evaluate the robustness of the results. 
Table 3. Optimal portfolios with EDH, comparing the years 2018, 2019 and 2020 and two alternative values of the risk aversion parameter: $\tau=0.5$ and $\tau=5$.

\begin{tabular}{cccccccccccc}
\hline Year & $\boldsymbol{\tau}$ & BTC & BCH & LTC & ETH & BNB & LNK & XRP & EOS & TRX & XLM \\
\hline 2018 & 0.5 & 0.05 & 0.06 & 0.10 & 0.11 & 0.11 & 0.06 & 0.14 & 0.13 & 0.06 & 0.17 \\
2018 & 5 & 0.05 & 0.06 & 0.10 & 0.11 & 0.11 & 0.06 & 0.14 & 0.13 & 0.06 & 0.17 \\
2019 & 0.5 & 0.13 & 0.14 & 0.08 & 0.09 & 0.07 & 0.08 & 0.10 & 0.10 & 0.11 & 0.10 \\
2019 & 5 & 0.13 & 0.14 & 0.09 & 0.09 & 0.07 & 0.08 & 0.10 & 0.10 & 0.11 & 0.10 \\
2020 & 0.5 & 0.19 & 0.03 & 0.11 & 0.03 & 0.09 & 0.06 & 0.19 & 0.09 & 0.07 & 0.13 \\
2020 & 5 & 0.19 & 0.02 & 0.12 & 0.04 & 0.10 & 0.07 & 0.19 & 0.07 & 0.06 & 0.13 \\
\hline
\end{tabular}

Table 4. Optimal portfolios with Markowitz, comparing the years 2018, 2019 and 2020 and two alternative values of the risk aversion parameter: $\tau=0.5$ and $\tau=5$.

\begin{tabular}{cccccccccccc}
\hline Year & $\boldsymbol{\tau}$ & BTC & BCH & LTC & ETH & BNB & LNK & XRP & EOS & TRX & XLM \\
\hline 2018 & 0.5 & 0.80 & 0 & 0 & 0.15 & 0 & 0.02 & 0.02 & 0 & 0 & 0 \\
2018 & 5 & 0.80 & 0 & 0 & 0.17 & 0 & 0.01 & 0.01 & 0 & 0 & 0 \\
2019 & 0.5 & 0.77 & 0 & 0 & 0 & 0.12 & 0.03 & 0.08 & 0 & 0 & 0 \\
2019 & 5 & 0.76 & 0 & 0 & 0 & 0.11 & 0.01 & 0.12 & 0 & 0 & 0 \\
2020 & 0.5 & 0.57 & 0 & 0 & 0 & 0.04 & 0.02 & 0.36 & 0 & 0 & 0.01 \\
2020 & 5 & 0.53 & 0 & 0 & 0 & 0.04 & 0.01 & 0.40 & 0 & 0 & 0.02 \\
\hline
\end{tabular}

Table 3 shows that the selected portfolio using the EDH method is different over the years. For instance, in 2018, XLM followed by XRP recorded the highest weights, while in 2019, the highest weights were recorded by BCH followed by BTC and, in 2020, BTC and $\mathrm{XRP}$ were jointly tied as the top portfolio-weighted crypto assets. These results corroborate the findings of $[43,44]$ which indicates the prevalence of BTC during the COVID-19-induced crisis. The authors argue that the importance of BTC to a portfolio of crypto assets especially in 2020 is due to its relatively higher stability during the COVID-19 pandemic.

The results from Table 3 suggests that the optimal portfolio weights under the EDH method do not change significantly for the different levels of the risk aversion. Thus, the $\mathrm{EDH}$ method is very robust to the risk aversion parameter. From a statistical viewpoint, the low sensitiveness of the weights to the risk aversion parameter indicates that the tail risk prevails over the expected systematic risk.

The results of the Markowitz in Table 4 shows that, in all years, BTC constitutes the largest part of a portfolio of crypto assets. The comparison of these results with those in Table 3 clearly indicates that, when tail risks are not considered, as in Markowitz portfolios, investors place high weights in BTC, the most capitalized cryptocurrency. However, when tail risk is incorporated in the portfolio optimization, as in our proposal, the weights are more balanced, and such portfolio construction are better against the (tail and systemic) risk of shocks. In other words, by considering tail risk, along with systematic and systemic risk, as a constraint in Markowitz' portfolio selection, we obtain a more diversified portfolio. This is consistent with the fact that when investors spread investments among more assets, crisis times impact less.

To summarize, our proposed portfolio selection method is more suitable than the Markowitz method in optimizing portfolio diversification. This is especially true in the presence of relevant components of tail risk, along with systematic and systemic risk. In this context, the proposed method is particularly effective in minimizing each risk type in a portfolio diversification strategy.

\section{Conclusions and Future Research}

The main goal in choosing an optimal portfolio structure is to help individuals to decide in which assets to invest and in which proportions. There are many aspects which can influence people's decisions. One of them is the perceived risk, which should be measured appropriately. In this paper we consider measuring tail risk. Taking it into account is particularly important for highly volatile and relatively illiquid market such 
as crypto asset markets. We proposed a way to measure all the three risks together, and embed them as constraints in a portfolio optimization problem.

Our empirical findings show that the portfolio weights calculated by our models lead to portfolios that are more diversified than those obtained with the classical Markowitz approach. Under our approach, investors do not concentrate their portfolio on Bitcoin as in the standard case, but diversify and, therefore, obtain a better hedge to shocks.

Further research should consider the application of the proposed method to other asset classes, and further comparison with standard methods, to better show where the advantages of the proposed method are most evident.

In particular, as further data becomes available, it would be very important to compare the performance of the proposed method, in an out-of-sample perspective, against other portfolios, such as the basic mean-variance portfolio and the equally weighted portfolio, which in other contexts have proved to give good results (see, e.g., [6]).

Author Contributions: Conceptualization, F.M.; methodology, F.M. and D.F.A.; software, D.F.A.; validation, F.M. and D.F.A.; formal analysis, D.F.A.; investigation, F.M. and D.F.A. and P.G.; resources, F.M.; data curation, F.M.; writing—original draft preparation, F.M. and D.F.A.; writing-review and editing, P.G.; visualization, F.M. and D.F.A.; supervision, P.G.; project administration, D.F.A. and P.G.; funding acquisition, P.G.; supervision, P.G. All authors have read and agreed to the published version of the manuscript.

Funding: This research received no external funding.

Institutional Review Board Statement: Not applicable.

Informed Consent Statement: Not applicable.

Data Availability Statement: The data and the material used in the paper is publicly available at https: / / coinmarketcap.com (accessed on 21 January 2021), but can also obtained from the authors upon request.

Acknowledgments: We would like to thank the editor and referees for their comments on an earlier version of this paper.

Conflicts of Interest: The authors declare no conflict of interest.

\section{References}

1. Markowitz, H. The Utility of Wealth. J. Political Econ. 1952, 60, 151-158. [CrossRef]

2. Elton, E.J.; Gruber, M.J.; Spitzer, J. Improved Estimates of Correlation Coefficients and their Impact on Optimum Portfolios. Eur. Financ. Manag. 2006, 12, 303-318. [CrossRef]

3. Artzner, P.; Delbaen, F.; Eber, J.M.; Heath, D. Coherent Measures of Risk. Math. Financ. 1999, 9, 203-228. [CrossRef]

4. Bellini, F.; Di Bernardino, E. Risk Management with Expectiles. Eur. J. Financ. 2017, 23, 487-506. [CrossRef]

5. Cesarone, F; Tardella, F. Equal Risk Bounding Is Better than Risk Parity for Portfolio Selection. J. Glob. Optim. 2017, 68, 439-461. [CrossRef]

6. DeMiguel, V.; Garlappi, L.; Uppal, R. Optimal Versus Naive Diversification: How Inefficient is the 1/N Portfolio Strategy? Rev. Financ. Stud. 2009, 22, 1915-1953. [CrossRef]

7. Maillard, S.; Roncalli, T.; Teiletche, J. The Properties of Equally Weighted Risk Contribution Portfolios. J. Portf. Manag. 2010, 36, 60-70. [CrossRef]

8. Castro, F.; Gago, J.; Hartillo, I.; Puerto, J.; Ucha, J. An Algebraic Approach to Integer Portfolio Problems. Eur. J. Oper. Res. 2011, 210, 647-659. [CrossRef]

9. Kolm, P.N.; Tütüncü, R.; Fabozzi, F.J. 60 Years of Portfolio Optimization: Practical Challenges and Current Trends. Eur. J. Oper. Res. 2014, 234, 356-371. [CrossRef]

10. Lynch, A.W.; Tan, S. Explaining the Magnitude of Liquidity Premia: The Roles of Return Predictability, Wealth Shocks, and State-Dependent Transaction Costs. J. Financ. 2011, 66, 1329-1368. [CrossRef]

11. Mansini, R.; Ogryczak, W.; Speranza, M.G. Twenty Years of Linear Programming Based Portfolio Optimization. Eur. J. Oper. Res. 2014, 234, 518-535. [CrossRef]

12. Mansini, R.; Ogryczak, W.; Speranza, M.G. Portfolio Optimization with Transaction Costs. In Linear and Mixed Integer Programming for Portfolio Optimization; Springer: Berlin/Heidelberg, Germany, 2015; pp. 47-62.

13. Kadan, O.; Liu, F; Liu, S. Generalized Systematic Risk. Am. Econ. J. Microecon. 2016, 8, 86-127. [CrossRef]

14. Härdle, W.K.; Wang, W.; Yu, L. TENET: Tail-Event Driven NETwork Risk. J. Econom. 2016, 192, 499-513. [CrossRef] 
15. Battiston, S.; Gatti, D.D.; Gallegati, M.; Greenwald, B.; Stiglitz, J.E. Liaisons Dangereuses: Increasing Connectivity, Risk Sharing, and Systemic Risk. J. Econ. Dyn. Control 2012, 36, 1121-1141. [CrossRef]

16. Ladley, D. Contagion and Risk Sharing on the Inter-bank Market. J. Econ. Dyn. Control 2013, 37, 1384-1400. [CrossRef]

17. Elliott, M.; Golub, B.; Jackson, M.O. Financial Networks and Contagion. Am. Econ. Rev. 2014, 104, 3115-3153. [CrossRef]

18. Acemoglu, D.; Ozdaglar, A.; Tahbaz-Salehi, A. Systemic Risk and Stability in Financial Networks. Am. Econ. Rev. 2015, 105, 564-608. [CrossRef]

19. Billio, M.; Getmansky, M.; Lo, A.W.; Pelizzon, L. Econometric Measures of Connectedness and Systemic Risk in the Finance and Insurance Sectors. J. Financ. Econ. 2012, 104, 535-559. [CrossRef]

20. Diebold, F.; Yilmaz, K. On the Network Topology of Variance Decompositions: Measuring the Connectedness of Financial Firms. J. Econom. 2014, 182, 119-134. [CrossRef]

21. Ahelegbey, D.F. The Econometrics of Bayesian Graphical Models: A Review With Financial Application. J. Netw. Theory Financ. 2016, 2, 1-33. [CrossRef]

22. Ahelegbey, D.F.; Billio, M.; Casarin, R. Bayesian Graphical Models for Structural Vector Autoregressive Processes. J. Appl. Econom. 2016, 31, 357-386. [CrossRef]

23. Rietz, T.A. The Equity Risk Premium a Solution. J. Monet. Econ. 1988, 22, 117-131. [CrossRef]

24. Barro, R.J. Rare Disasters and Asset Markets in the Twentieth Century. Q. J. Econ. 2006, 121, 823-866. [CrossRef]

25. Gillman, M.; Kejak, M.; Pakoš, M. Learning about Rare Disasters: Implications for Consumptions and Asset Prices. Rev. Financ. 2015, 19, 1053-1104. [CrossRef]

26. Gabaix, X. Variable Rare Disasters: An Exactly Solved Model for Ten Puzzles in Macro-Finance. Q. J. Econ. 2012, 127, 645-700. [CrossRef]

27. Wachter, J.A. Can Time-Varying Risk of Rare Disasters Explain Aggregate Stock Market Volatility? J. Financ. 2013, 68, 987-1035. [CrossRef]

28. Brandt, M.W.; Santa-Clara, P. Dynamic Portfolio Selection by Augmenting the Asset Space. J. Financ. 2006, 61, $2187-2217$. [CrossRef]

29. Cruz-Reyes, L.; Trejo, C.M.; Irrarragorri, F.L.; Santillán, C.G.G. A Decision Support System Framework for Public Project Portfolio Selection with Argumentation Theory. In Recent Advances on Hybrid Approaches for Designing Intelligent Systems; Springer: Berlin/Heidelberg, Germany, 2014; pp. 467-479.

30. Harvey, C.R.; Liechty, J.C.; Liechty, M.W.; Müller, P. Portfolio Selection with Higher Moments. Quant. Financ. 2010, 10, 469-485. [CrossRef]

31. Lwin, K.; Qu, R. A Hybrid Algorithm for Constrained Portfolio Selection Problems. Appl. Intell. 2013, 39, 251-266. [CrossRef]

32. Perez, F.; Gomez, T. Multiobjective Project Portfolio Selection with Fuzzy Constraints. Ann. Oper. Res. 2016, 245, 7-29. [CrossRef]

33. Ling, A.; Sun, J.; Wang, M. Robust Multi-period Portfolio Selection Based on Downside Risk with Asymmetrically Distributed Uncertainty Set. Eur. J. Oper. Res. 2020, 285, 81-95. [CrossRef]

34. Jiang, C.; Ma, Y.; An, Y. Portfolio Selection with a Systematic Skewness Constraint. North Am. J. Econ. Financ. 2016, 37, 393-405. [CrossRef]

35. Campbell, R.; Huisman, R.; Koedijk, K. Optimal Portfolio Selection in a Value-at-Risk Framework. J. Bank. Financ. 2001, 25, 1789-1804. [CrossRef]

36. Li, Q.; Bai, Y.; Yan, X.; Zhang, W. Portfolio Selection with the Effect of Systematic Risk Diversification: Formulation and Accelerated Gradient Algorithm. Optim. Methods Softw. 2019, 34, 612-633. [CrossRef]

37. Li, Y.; Zhu, S.; Li, D.; Li, D. Active Allocation of Systematic Risk and Control of Risk Sensitivity in Portfolio Optimization. Eur. J. Oper. Res. 2013, 228, 556-570. [CrossRef]

38. Zhu, S.; Li, D.; Sun, X. Portfolio Selection with Marginal Risk Control. J. Comput. Financ. 2010, 14, 3. [CrossRef]

39. Grinold, R.C.; Kahn, R.N. Active Portfolio Management: A Quantitative Approach for Producing Superior Returns and Controlling Risk; McGraw Hill: New York, NY, USA, 1999.

40. Ahelegbey, D.F.; Giudici, P.; Mojtahedi, F. Tail Risk Measurement in Crypto-Asset Markets. Int. Rev. Financ. Anal. 2021, $73,101604$. [CrossRef]

41. Hardle, W.; Trimborn, S. CRIX an Index for Cryptocurrencies. J. Empir. Financ. 2018, 49, 107-122.

42. Kwapien, J.; Watorek, M.; Drozd, S. Cryptocurrency market consolidation in 2020-2021. Entropy 2021, 12, 1674. [CrossRef]

43. Huynh, T.L.D.; Nasir, M.A.; Vo, X.V.; Nguyen, T.T. Small things matter most: The spillover effects in the cryptocurrency market and gold as a silver bullet. N. Am. J. Econ. Financ. 2020, 54, 101277. [CrossRef]

44. Iqbal, N.; Fareed, Z.; Wan, G.; Shahzad, F. Asymmetric nexus between COVID-19 outbreak in the world and cryptocurrency market. Int. Rev. Financ. Anal. 2021, 73, 101613. [CrossRef] 